\title{
Response to adrenocorticotropic hormone or corticotrophin-releasing hormone and vasopressin in lactating cows fed an immunomodulatory supplement under thermoneutral or acute heat stress conditions
}

\author{
M. L. McBride, ${ }^{1} \odot$ N. C. Burdick Sanchez, ${ }^{2} \odot$ J. A. Carroll, ${ }^{2} \odot$ P. R. Broadway, ${ }^{2}$ X. A. Ortiz, ${ }^{1 *}$ J. L. Collier, ${ }^{1} \odot$

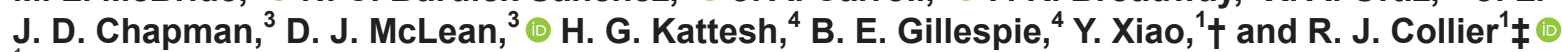 \\ ${ }^{1}$ School of Animal and Comparative Biomedical Sciences, University of Arizona, Tucson 85719 \\ ${ }^{2}$ USDA Agricultural Research Service Livestock Issues Research Unit, Lubbock, TX 79403 \\ ${ }^{3}$ Phibro Animal Health Corp., Teaneck, NJ 07666 \\ ${ }^{4}$ Department of Animal Science, University of Tennessee, Knoxville 37996
}

\section{ABSTRACT}

Adrenal responsiveness was tested in nonpregnant, lactating Holstein dairy cows fed diets supplemented with OmniGen-AF (OG; Phibro Animal Health Corp., Teaneck, NJ), an immune modulator, and in nonsupplemented control (CON) cows following bolus infusions of a combination of corticotropin-releasing hormone (CRH; $0.3 \mu \mathrm{g} / \mathrm{kg}$ of BW) and arginine vasopressin (VP; $1.0 \mu \mathrm{g} / \mathrm{kg}$ of BW) or ACTH $(0.1 \mathrm{IU} / \mathrm{kg}$ of BW) in 2 environments: thermoneutral [TN; temperature-humidity index (THI) <60] for $24 \mathrm{~h} / \mathrm{d}$ and heat stress (HS; THI $>68$ for $17 \mathrm{~h} / \mathrm{d})$. Cows (506) were initially fed OG $(\mathrm{n}=$ $254)$ or CON $(\mathrm{n}=252)$ diets for $44 \mathrm{~d}$ before selection of a subgroup of cows $(\mathrm{n}=12 ; 6 \mathrm{OG}, 6 \mathrm{CON})$ for the study. The 2 subgroups were balanced for parity, milk yield, and days in milk. All cows were transported to and housed in 2 environmentally controlled rooms at the University of Arizona Agricultural Research Complex (Tucson). Cows were given $3 \mathrm{~d}$ to acclimate to the rooms and then underwent $12 \mathrm{~d}$ of $\mathrm{TN}$ conditions and then $8 \mathrm{~d}$ of HS conditions for a total of $24 \mathrm{~d}$ on experiment. Cows were infused with CRH-VP on d 9 of TN and on d 1 of HS and with ACTH on d 10 of TN and on d 2 of HS. Hormone infusions took place at $1000 \mathrm{~h}(0 \mathrm{~h})$ on each infusion day. Blood samples, taken in 30-min intervals, were first collected at $0800 \mathrm{~h}(-2$ h) and were drawn until $1800 \mathrm{~h}(8 \mathrm{~h})$. Before infusion, serum progesterone was elevated in OG cows compared with CON cows. Infusion of releasing factors (CRH-VP or ACTH) caused increases in serum cortisol and progesterone, but cortisol release was greater in $\mathrm{CON}$ cows

\footnotetext{
Received September 5, 2019.

Accepted February 10, 2020.

*Current address: Waldino Ramon Lovera, 6067 c/ R I 12 de Mayo, Asunción, Paraguay.

†Current address: University of Florida, Gainesville, FL 32611.

‡Corresponding author: rcollier@ag.arizona.edu
}

than in OG cows during HS, whereas progesterone did not differ between the 2 treatments. Serum ACTH increased following infusion of releasing factors, but this increase was greater following CRH-VP infusion than ACTH infusion. Serum bovine corticosteroid-binding globulin also increased following infusion of releasing factors in both treatment groups, but this increase was greater during $\mathrm{HS}$ in cows fed OG. The free cortisol index (FCI) increased following CRH-VP and ACTH and was higher in $\mathrm{HS}$ than in $\mathrm{TN}$ for both $\mathrm{OG}$ and $\mathrm{CON}$ cows. However, the FCI response was blunted in OG cows compared with CON cows during HS. Heat stress enhanced the adrenal response to releasing factors. Additionally, the adrenal cortisol and FCI response to releasing factors was reduced during acute heat stress in cows fed OG. Collectively, these data suggest that OG supplementation reduced the adrenal responsiveness to factors regulating cortisol secretion during acute HS.

Key words: endocrine response, heat stress, immunemodulatory agent, lactating cow

\section{INTRODUCTION}

The stress response is driven by the hypothalamicpituitary-adrenal axis, a negative feedback loop activated first in the hypothalamus when an environmental factor causes cattle to become stressed (Collier and Gebremedhin, 2015). Neuronal tissue within the hypothalamus secretes 2 known hormones activated by a stressor: corticotropin-releasing hormone $(\mathbf{C R H})$, also known as corticotropin-releasing factor, and vasopressin (VP), also known as antidiuretic hormone. Both of these hormones synergistically play a significant role in communicating with the corticotropic cells (Anton and Solcan, 2012) of the anterior pituitary gland to secrete ACTH. Once secreted from the pituitary gland, ACTH then binds to ACTH receptors located in the adrenal cortex. Cortisol secretion is the final secretory arm of 
the hypothalamic-pituitary axis. The biological actions of cortisol are to maintain physiologic function during stress. It is the concentration of cortisol that quantitatively indicates the level of stress experienced by cattle due to hypothalamic-pituitary axis activation. However, corticosteroid-binding globulin (CBG) also plays a role in determining how much circulating cortisol is free to bind to receptors (Siiteri et al., 1982). Under normal physiologic conditions, the majority of circulating cortisol is bound to this glycoprotein produced by the liver (Carroll et al., 2011). The amount of unbound cortisol (free cortisol index; FCI) can be calculated using the ratio of serum total cortisol to CBG concentration (Le Roux et al., 2002, 2003).

It is well established that acute but not chronic heat stress (HS) activates the hypothalamic-pituitary axis and rapidly increases plasma cortisol in dairy cattle (Gwazdauskas et al., 1972; Collier et al., 1982; Collier and Gebremedhin, 2015). Furthermore, this is associated with the acute heat shock response; in fact, binding of cortisol to its receptor is associated with release of intracellular heat shock proteins and initiation of RNA synthesis for production of new heat shock proteins (Collier et al., 2008).

OmniGen-AF (OG; Phibro Animal Health Corp., Teaneck, NJ) is an immune modulatory feed additive that enhances immune response and may mitigate the effects of HS on lactating dairy cows by altering the stress response (Wang et al., 2007; Brandão et al., 2016; Fabris et al., 2017). A previous study by Hall et al. (2018) investigated the effect of OG in lactating multiparous cows subjected to HS on milk yield, feed intake, water intake, rectal temperature, respiration rates, and serum cortisol. These researchers demonstrated that OG reduced physiological responses to HS, increased feed intake, and reduced the cortisol response to acute but not chronic HS (Hall et al., 2018). In addition, serum ACTH concentrations in cows fed OG were markedly elevated despite the lower cortisol response to acute HS. These findings warranted further investigation into whether the feed additive alters the hypothalamic-pituitary axis. Therefore, we tested the hypothesis that adrenal response (cortisol, progesterone, $\mathrm{CBG}$, and $\mathrm{FCI}$ ) to $\mathrm{ACTH}$ or $\mathrm{CRH}$ is altered during the TN period and the acute portion of HS (first 3 d) in cows fed OG.

\section{MATERIALS AND METHODS}

\section{On-Farm Prestudy Period}

All aspects of this protocol were approved by the Animal Care and Use Committee of the University of
Arizona. The on-dairy prestudy period was needed to elicit an immune response to OG before arrival at the University of Arizona Agricultural Research Complex. Previous studies have established that prefeeding OG for $45 \mathrm{~d}$ before the administration of a stress was necessary to demonstrate differences in markers of immune function (Wang et al., 2004; Ryman et al., 2013; OrtizMarty et al., 2017). In this study, 506 lactating Holstein cows from a commercial dairy (Caballero Dairy, Eloy, AZ) were separated into 2 groups and fed either the basal silage-based diet (control, $\mathbf{C O N} ; \mathrm{n}=252$ cows) or the basal diet plus the supplement (OG, $56 \mathrm{~g} / \mathrm{h}$ per day; $\mathrm{n}=254$ cows). OmniGen-AF contains a mixture of silicon dioxide, calcium aluminosilicate, sodium aluminosilicate, brewers dehydrated yeast, mineral oil, calcium carbonate, rice hulls, niacin supplement, biotin, d-calcium pantothenate, vitamin $\mathrm{B}_{12}$ supplement, choline chloride, thiamine mononitrate, pyridoxine hydrochloride, riboflavin 5-phosphate, and folic acid (full formulation is proprietary; Phibro Animal Health Corp.).

At the dairy, cows were housed in a dry lot dairy with Saudi barns that were cooled by an Advanced Dairy Systems Shade Tracker (Chandler, AZ), an oscillating evaporative cooling system. Because pen and treatment (TRT) were confounded in the on-farm prestudy period, no comparisons of blood hormones or metabolites were made. Following $44 \mathrm{~d}$ of the $\mathrm{CON}$ or OG diets, 6 nonpregnant cows were selected from each group to be used for the environmental and hormonal challenge study at the University of Arizona. Selected cows in each group were balanced for milk yield, parity, and DIM (Table 1) and were then transferred from Eloy, Arizona, to Tucson, Arizona, for the environmental room component, which lasted $24 \mathrm{~d}$ (Table 2). Average DIM $( \pm$ SE) was $152.3 \pm 3.9$ for OG and $153.7 \pm 5.4$ for CON. Average parity was $2.8 \pm 0.8$ for $\mathrm{OG}$ and 2.8 \pm 1.0 for CON. Average milk yield $(\mathrm{kg} / \mathrm{d})$ was $50.8 \pm$ 1.9 for $\mathrm{OG}$ and $51.0 \pm 4.0$ for $\mathrm{CON}$.

Table 1. Body weight, parity, DIM, and milk yield for cows selected for the environmental room component ${ }^{1}$

\begin{tabular}{lrrrrr}
\hline & \multicolumn{2}{c}{ OG } & & \multicolumn{2}{c}{ CON } \\
\cline { 2 - 3 } \cline { 5 - 6 } Item & Mean & SEM & & Mean & \multirow{2}{*}{ SEM } \\
\hline BW $(\mathrm{kg})$ & 667.5 & 61.8 & & 674.7 & 50.5 \\
Parity & 2.8 & 0.8 & & 2.8 & 1.0 \\
DIM & 152.3 & 3.9 & & 153.7 & 5.4 \\
Milk yield $(\mathrm{kg})$ & 50.8 & 1.9 & & 51.0 & 4.0
\end{tabular}

${ }^{1} \mathrm{CON}=$ basal silage-based $\operatorname{diet}(\mathrm{n}=252 \mathrm{cows}) . \mathrm{OG}=$ basal diet supplemented with OmniGen-AF (Phibro Animal Health Corp., Teaneck, NJ; $56 \mathrm{~g} / \mathrm{h}$ per day; $\mathrm{n}=254$ cows). 


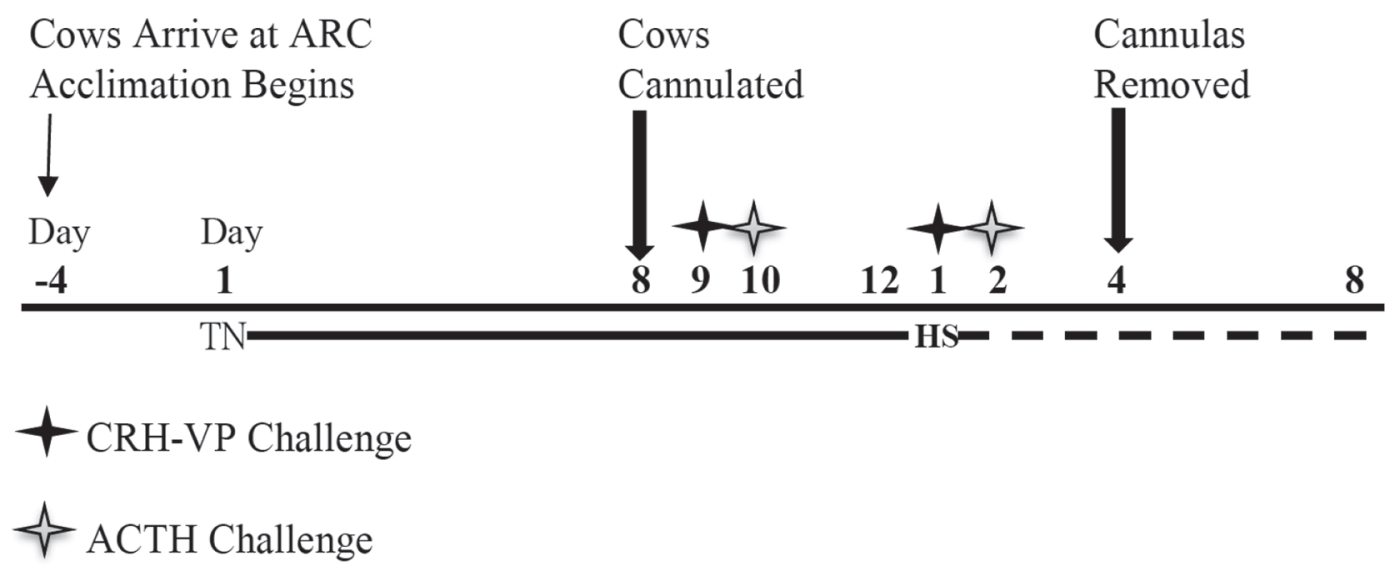

Figure 1. Timeline of the environmental room portion of the study. ARC = University of Arizona Agricultural Research Complex; CRH-VP $=$ corticotropin-releasing hormone and vasopressin. $\mathrm{TN}=$ thermoneutral (temperature-humidity index $<68$ ); HS $=$ heat stress $($ temperaturehumidity index $>68$ for $12 \mathrm{~h} / \mathrm{d}$ ).

\section{Environmental and Hormonal Challenge Study}

The study was conducted at the Agricultural Research Complex at the University of Arizona. The overall design of this portion of the study was a $2 \times 2$ factorial $[$ TRT $\times$ environment $(\mathbf{E N V})$ ], with the ACTH or CRH-VP infusion layered on top of the factorial. Upon arrival at the facility, all 12 cows were weighed, fitted with halters, and moved to their individually assigned tiestalls. Cows were randomly assigned by coin toss to 1 of 2 environmentally controlled rooms based on their previously assigned diet (3 OG and $3 \mathrm{CON}$ per room). All cows remained on their respective diets for

Table 2. Ingredients and chemical composition of the diet ${ }^{1}$

\begin{tabular}{lr}
\hline Item & Value \\
\hline Ingredient (\% of DM) & \\
Alfalfa hay & 65.02 \\
Corn, steam flaked & 22.12 \\
Whole cottonseed & 7.28 \\
Distillers grains, dry & 2.58 \\
Supplement RS-1299 & 2.04 \\
Maxxer & 0.96 \\
Chemical analysis & \\
CP (\%) & 19.75 \\
NDF (\%) & 25.39 \\
ADF (\%) & 19.75 \\
Fat (\%) & 4.74 \\
DM (\%) & 53.00 \\
NE & 1.76 \\
\hline
\end{tabular}

${ }^{1}$ Diet DM averaged $53 \%$ by weight of DM and moisture, including added water.

${ }^{2}$ The supplement contained $1.14 \%$ fat, $10.42 \%$ Ca, $4.49 \% \mathrm{P}, 3.80 \% \mathrm{Mg}$, $0.49 \%$ S, $0.19 \%$ K, $15.83 \% \mathrm{Na}, 7.52 \%$ Cl, 2,029.06 mg/kg Zn, $1,991.82$ $\mathrm{mg} / \mathrm{kg} \mathrm{Mn}, 974.24 \mathrm{mg} / \mathrm{kg} \mathrm{Fe}, 583.45 \mathrm{mg} / \mathrm{kg} \mathrm{Cu}, 67.86 \mathrm{mg} / \mathrm{kg}$ Co, $12.28 \mathrm{mg} / \mathrm{kg}$ Se, $6.81 \mathrm{mg} / \mathrm{kg}$ Mo, $43.68 \mathrm{mg} / \mathrm{kg} \mathrm{I}, 304.9 \mathrm{IU} / \mathrm{g}$ vitamin A, $30.2 \mathrm{IU} / \mathrm{g}$ vitamin $\mathrm{D}$, and $1.0 \mathrm{IU} / \mathrm{g}$ vitamin $\mathrm{E}$.

${ }^{3}$ Calcium salts of palm oil (Tarome Inc., Eloy, AZ). the duration of the study. Both rooms were monitored throughout the night via cameras accessible through an information technology network to ensure the safety of the cows. The dairy cows remained in their assigned stalls for the duration of the study, which consisted of $12 \mathrm{~d}$ of TN and $9 \mathrm{~d}$ of HS (Figure 1). To ensure that the cows fully recovered from being moved to the environmental rooms, there was a 3 -d acclimation period under TN conditions before the start of the thermoneutral period.

Each room was used to test $2 \mathrm{ENV}$ : thermoneutral (TN) and HS. Using the temperature-humidity index (THI) threshold index created by Zimbelman et al. (2009), the THI during the TN portion of the study was kept below the HS threshold $(<68)$ for lactating dairy cows. All cows were kept at TN during the acclimation period. During the HS portion, THI values were kept above the THI stress threshold (>68) for $12 \mathrm{~h} / \mathrm{d}$, indicating that the cows were experiencing a heat-stressed ENV. The THI was set to establish a circadian temperature cycle that always remained THI $<68$ for $24 \mathrm{~h} / \mathrm{d}$ for the TN ENV and THI $>68$ for $12 \mathrm{~h} / \mathrm{d}$ for the HS ENV. Environmental factors of temperature, relative humidity (RH), and THI were automatically recorded using data loggers. In addition, physiological factors including respiration rate (RR), skin temperature, rectal temperature (RT), milk production, milk composition, feed intake, and water consumption were quantitatively recorded. Respiration rates, skin temperatures, and RT were recorded thrice daily at 1200, 1400, and $1600 \mathrm{~h}$. Respiration rate was calculated by number of breaths observed via expansion of the thoracic cavity during $15 \mathrm{~s}$ of observation and was multiplied by 4 . Average skin temperature was calculated from temperatures recorded at the rump, head, and shoulder using a Ray- 
tek infrared thermometer (Raytek Corp., Santa Cruz, CA). The skin temperatures of these 3 locations were averaged into a single skin temperature for statistical analysis. Rectal temperatures were obtained manually using a high-performance thermometer (GLA M700, GLA Agricultural Electronics, San Luis Obispo, CA). Temperature and $\mathrm{RH}$ were recorded using 3 Hobo U23 Pro V2 loggers (Onset Computer Corp., Bourne, MA) in each room. The $\mathrm{TN}$ temperatures ranged from $11.8^{\circ} \mathrm{C}$ to $25.7^{\circ} \mathrm{C}$, and HS temperatures ranged from $19.2^{\circ} \mathrm{C}$ to $36.1^{\circ} \mathrm{C}$. Relative humidity percentage ranged from 29.2 to 87.7 in the TN ENV and from 17.6 to 88.2 in the HS ENV. Temperature-humidity index is a calculation based on temperature and RH. The equation used to determine this value is $\mathrm{THI}=(1.8 \times \mathrm{Tdb}+32)-(0.55$ $-0.0055 \times \mathrm{RH}) \times(1.8 \times \mathrm{Tdb}-26)$, where Tdb is dry bulb temperature $\left({ }^{\circ} \mathrm{C}\right)$ and $\mathrm{RH}$ is relative humidity $(\%$; Zimbelman et al., 2009).

Milking and feeding occurred twice daily at 0500 and $1700 \mathrm{~h}$ at cows' individual stalls. All 12 cows were fed twice daily and consumed the same hay-based TMR (Table 2) top-dressed with $25 \mathrm{~g}$ of molasses during each feeding. For the OG cows $(\mathrm{n}=6), 28 \mathrm{~g}$ of the feed additive was added to the top quarter of the feed before being top-dressed with molasses during each feeding for a total of $56 \mathrm{~g} /$ head per day. Orts of each meal were collected, weighed, and recorded at 0445 and $1645 \mathrm{~h}$ daily. Positive-displacement water meters at each individual stall recorded the total volume dispensed to the bowls. Water was dispensed when a lever located inside the individual water bowls was compressed. These data were collected from the water meter register during each morning feeding and milking. After each milking, the total milk produced was weighed and recorded. A vial containing a preservative (bronopol tablet; $\mathrm{D} \& \mathrm{~F}$ Control Systems, San Ramon, CA) was used to collect a small sample of milk from each cow and stored at $4^{\circ} \mathrm{C}$ until the end of the week. The samples collected were analyzed by Arizona DHIA (Tempe, AZ) for milk composition (protein percentage, fat percentage, SCC, $\mathrm{SNF}$, and lactose).

\section{Hypothalamic-Pituitary Axis Challenge}

On d 8 of TN, all cows were surgically fitted with cannulas into the jugular vein (Carroll et al., 2009; Figure 1). The cannulas were used to collect blood samples as well as administer the bolus infusion of synthetic hormones during each infusion. During the last few days of $\mathrm{TN}$ and the first $2 \mathrm{~d}$ of $\mathrm{HS}$, all cows were given intravenous boluses of CRH-VP or ACTH (Figure 1) to test the cortisol and progesterone adrenal response (Lay et al., 1996; Buntyn et al., 2016) to TN and acute HS conditions in $\mathrm{CON}$ and $\mathrm{OG}$ animals. Blood was sampled at 21 different time points for each of the 4 infusions. Specifically, blood was sampled from $-2 \mathrm{~h}$ $(0800 \mathrm{~h})$ to $8 \mathrm{~h}(1800 \mathrm{~h})$ at 30 -min intervals for each infusion. At time point $0 \mathrm{~h}(1000 \mathrm{~h})$ for each infusion day, a blood sample was collected before administering the bolus injection of the synthetic hormones. The first day of the infusion (d 9 of $\mathrm{TN}$ ) consisted of infusing all cows with a bolus of bovine $\mathrm{CRH}$ (Bachem, Torrance, $\mathrm{CA} ; 0.3 \mathrm{ug} / \mathrm{kg}$ of $\mathrm{BW}$ diluted in sterile saline) and bovine VP (Sigma-Aldrich, St. Louis, MO; $1 \mu \mathrm{g} / \mathrm{kg}$ of BW diluted in sterile saline). Vasopressin and $\mathrm{CRH}$ were given at the same time but via 2 different syringes in the TN ENV at $0 \mathrm{~h}$. The concentration of the 2 solutions was $100 \mu \mathrm{g} / \mathrm{mL}$ for $\mathrm{CRH}$ and $5 \mathrm{mg} / \mathrm{mL}$ for VP. Working doses were calculated to allow for administration of volumes between 1 and $3 \mathrm{~mL}$ per hormone infused per cow. On the second day of the infusion (d 10 of TN), a bolus injection of porcine ACTH (SigmaAldrich; $0.1 \mathrm{IU} / \mathrm{kg}$ of $\mathrm{BW}$ ) diluted in sterile saline at a concentration of $50 \mathrm{IU} / \mathrm{mL}$ was given in the TN ENV. The cows were then given $2 \mathrm{~d}$ of rest. On the first day of HS, cows were infused with $\mathrm{CRH}$ coupled with VP in the HS ENV, and on d 2 of HS all cows were infused with ACTH at the same doses infused in the TN ENV (Figure 1). Cannulas were removed from all cows on $\mathrm{d}$ 16 of the study, and the study was completed on d 20 .

Blood samples collected while the cows were on the environmental and hormonal challenge study were allowed to sit at room temperature for $30 \mathrm{~min}$ and then centrifuged using an Eppendorf 5804R (Eppendorf International, Hamburg, Germany) at 1,500 $\times g$ for $15 \mathrm{~m}$ at $4^{\circ} \mathrm{C}$ after collection to isolate the serum from each sample. Once collected, serum was aliquoted and stored in individual microfuge tubes at $-20^{\circ} \mathrm{C}$ until analyzed. To determine the effects of OG on adrenal function in lactating dairy cows, 4 blood analytes were measured in isolated serum: cortisol, ACTH, progesterone, and bovine CBG (bCBG). Progesterone (Eagle Biosciences, Nashua, NH), cortisol (Eagle Biosciences), and ACTH (NeoBioLab, Cambridge, MA) were analyzed using commercially available ELISA kits. The intra-assay and interassay coefficients of variation were 12 and $5 \%$ for progesterone, 14 and $7 \%$ for cortisol, and 13 and $12 \%$ for ACTH, respectively. Absorbances were read using a SpectraMax M2 spectrophotometer (Molecular Devices, Sunnyvale, CA), and data were collected using SoftMax Pro version 5.4.4 (Molecular Devices).

The bCBG was isolated and purified from bovine plasma (400 mL) using a series of 3 columns, Sepharose-HCAC (Sepharose 4B, Pharmacia, Piscataway, NJ, linked in-house with 11-hydroxy-3-one-pregn-4one-17 carboxylic acid, Sigma-Aldrich), concanavalin A-Sepharose 4B (Sigma-Aldrich), and HPLC DEAE (diethylaminoethyl anion exchange, TSK-DEAE 5-PW, 
LKB Bromma, Uppsala, Sweden), as described previously for porcine CBG (Roberts et al., 2003). The location of bCBG in column elutes was monitored by optical density at $280 \mathrm{~nm}$, presence of bCBG by ${ }^{3} \mathrm{H}-$ cortisol binding assay, and 1-dimensional SDS-PAGE. Pooled fractions of bCBG from the HPLC-DEAE column consisted of a polypeptide chain of approximately $59.7 \mathrm{kDa}$. After $\mathrm{N}$-acetyl deglycosolation, the apparent molecular weight was reduced to $41.6 \mathrm{kDa}$. The carbohydrate content of the native molecule was therefore estimated to be $28.5 \%$. This molecular weight determination is comparable with the theoretical molecular weight calculated from http://web.expasy.org/compute .pi/, which calculated a theoretical molecular weight of $42.6 \mathrm{kDa}$ and theoretical isoelectric point of 5.54.

The bCBG sequence was predicted using a BLAST search via NCBI using porcine CBG mRNA (NM_213812.1) against Bos taurus and resulted in a predicted mRNA sequence (XR_028138.2) from Bos taurus genomic sequence (NW_001494051). Mass spectrum analysis (liquid chromatography-tandem MS) of the peptide, performed at the University of Tennessee Medical Center (Knoxville, TN), was compared with XR_028138.2 and identified as bCBG. The bCBG showed sequence identities to CBG of other species: $95 \%$ to sheep, $79 \%$ to pig, $69 \%$ to rabbit, $57 \%$ to rat, and $55 \%$ to mouse.

Rabbit anti-bCBG serum was produced by Pacific Immunology Corp. (Ramona, CA). Two rabbits were initially injected with $120 \mu \mathrm{g}$ of bCBG. The animals were boosted 3 times with $60 \mu \mathrm{g}$ of bCBG. Serum was collected 2 wk after the final booster injection and stored at $-70^{\circ} \mathrm{C}$ until use. For the bCBG assay, the absorbances were read using an ELX808 (BioTek Instruments Inc., Winooski, VT) and data were collected using Gen5 software version 2.03.1 (BioTek Instruments Inc.). Parallelism in the ELISA assay between dilution of bovine serum (slope -1.91) and bCBG standards (slope -1.78) was demonstrated. Specificity of the antiserum for bCBG was tested by adding the following bovine serum constituents to the ELISA assay: albumin $(150 \mu \mathrm{g})$, fibronectin $(25 \mu \mathrm{g})$, hemoglobin $(100 \mu \mathrm{g})$, gamma globulin $(115 \mu \mathrm{g})$, and $\alpha / \beta$ globulin $(100 \mu \mathrm{g})$. Because CBG is a member of the serine proteinase inhibitor superfamily, other serine proteinase inhibitors including human $\alpha$-1-antitrypsin $(100-5,000$ $\mathrm{ng})$, human $\alpha$-1-antichymotrypsin (100-5,000 ng), and human thyroxine-binding globulin (10-1,000 ng) were also tested. Test levels were chosen to approximate the amount of individual protein that might be present at serum levels used in the assay. No cross-reactivity was observed. The immunoreactive species detected in bovine plasma by Western blotting showed the same relative migration as bCBG. A plot comparing the amount measured versus that expected when bCBG was added to plasma in the assay $(\mathrm{n}=12)$ yielded a slope of $1.06(\mathrm{r}=0.89)$. Intra- and interassay coefficients of variation $(\mathrm{n}=26)$ of pooled bovine serum were 7.7 and $8.5 \%$, respectively. The FCI was calculated by changing cortisol to nanomoles per liter then dividing it by bCBG expressed in milligrams per liter (Le Roux et al., 2002, 2003).

\section{Statistical Analysis}

Results obtained from the assays conducted in the laboratory (ACTH, cortisol, progesterone, glucose, insulin, nonesterified fatty acids, bCBG, and FCI) were analyzed using a mixed model of SAS (version 9.4; SAS Institute Inc., Cary, NC) according to the following equation:

$$
\begin{gathered}
Y_{i j m l}=\mu+T_{i}+B_{m}+C_{j}+H_{l}+A_{k}+T_{i} H_{l}+T_{i} C_{j} \\
+T_{i} C_{j} B_{m}+T_{i} C_{j} H_{l}+T_{i} B_{m} H_{l}+T_{i} B_{m} H_{l} C_{j}+e_{i j m l},
\end{gathered}
$$

where $Y_{\mathrm{ijml}}=$ individual data point, $\mu=$ overall mean, $\mathrm{T}_{\mathrm{i}}=$ fixed effect of TRT $(\mathrm{i}=\mathrm{CON}$ and $\mathrm{OG}), \mathrm{B}_{\mathrm{m}}=$ fixed effect of infusion $(\mathrm{m}=\mathrm{ACTH}$ and $\mathrm{CRH}-\mathrm{VP})$, $\mathrm{C}_{\mathrm{j}}=$ fixed climate effect $(\mathrm{j}=\mathrm{TN}$ and $\mathrm{HS}), \mathrm{H}_{1}=$ fixed effect of sample time $(-2 \mathrm{~h}=1$ and $+8 \mathrm{~h}=21), \mathrm{A}_{\mathrm{k}}=$ random effect of cow ( $\mathrm{k}=1$ to 12$)$, and $\mathrm{e}_{\mathrm{ijml}}=$ residual error. The Kenward-Roger option was used for determining degrees of freedom. A covariate (mean of the 3 samples taken before the challenge dose of ACTH or CRH-VP) was used for each of the hormone analyses. Repeated measurement was applied on cow as subject. A covariance structure with the smallest Akaike information criterion value was chosen from compound symmetry, Toeplitz, variance components, and autoregressive. Treatment effects were tested by means of the PDIFF option and were declared significant at $P$ $<0.05$. To meet the assumptions of ANOVA, we first identified and removed outliers with the absolute values of studentized residuals greater than 3 . The numbers of outliers removed were less than $0.5 \%$ of the total number of observations in each data set. Then, logarithmic, square root, reciprocal, and inverse square root transformation of data were tested. However, none of the 8 variables with or without transformation passed both normality and homogeneity of variance tests, which were carried out under the Univariate and GLM procedures, respectively. The TRT effects were tested by means of the PDIFF option and were declared significant at $P<0.05$. A tendency was declared for probability levels $P>0.06$ to $P<0.10$. An initial analysis of all $8 \mathrm{~h}$ of the postinfusion period was conducted to provide overall means for the variables measured, and 
Table 3. Mean production and physiological measures in cows fed the control (CON) or OG diets ${ }^{1}$ and subjected to TN or HS environments ${ }^{2}$

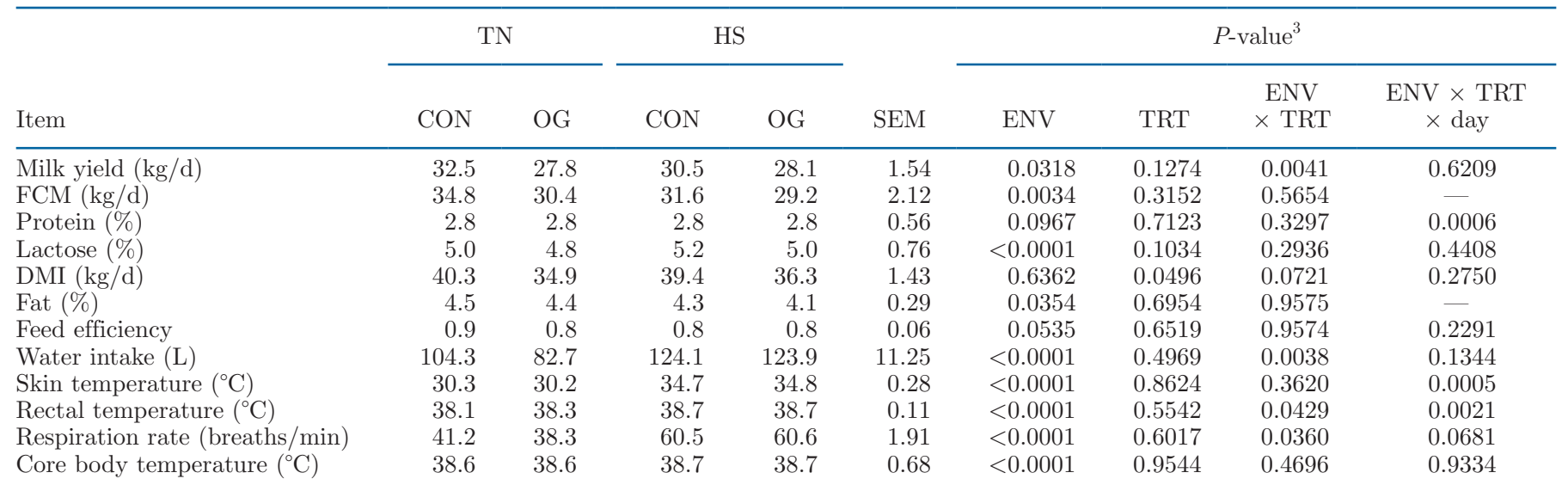

${ }^{1} \mathrm{CON}=$ basal silage-based diet $(\mathrm{n}=6$ cows). OG = basal diet supplemented with OmniGen-AF (Phibro Animal Health Corp., Teaneck, NJ; $56 \mathrm{~g} / \mathrm{h}$ per day; $\mathrm{n}=6$ cows).

${ }^{2} \mathrm{TN}=$ thermoneutral (temperature-humidity index $<68$ ). HS = heat stress (temperature-humidity index $>68$ for $12 \mathrm{~h} / \mathrm{d}$ ).

${ }^{3} \mathrm{ENV}=$ environment; TRT $=$ treatment.

a second analysis was conducted to provide means and tests of significance for the $4 \mathrm{~h}$ postinfusion for each infusion when analyte concentrations were changing in response to the infusion.

\section{RESULTS}

\section{On-Farm Prestudy Period}

The on-farm prestudy period was required to provide $45 \mathrm{~d}$ of exposure to OG to elicit an immune response in the OG animals before arrival at the Agricultural Research Complex for the environmental room challenge portion of the study. During the on-farm prestudy period, the cows remained in a single ENV, so effects of ENV were not evaluated. Additionally, because all CON cows were in one pen and all OG cows were in an adjoining pen, the effect of pen was confounded by dietary TRT. Therefore, the effects of dietary TRT on blood hormones and metabolites were not evaluated for the prestudy period. Thus, this portion of the study provided 2 pools of animals (OG and CON) to select animals for the environmental and hormonal challenge portion of the study.

\section{Environmental and Hormonal Challenge Study}

During the acclimation and TN periods of the study, the THI values for the rooms the cows were housed in never exceeded the stress threshold of 68. This kept mean core body temperatures of the cattle housed in the rooms in the normal range $(38.2 \pm 0.11)$ and mean $\mathrm{RR}(39.75 \pm 1.9)$ well below the stress response level of 60 breaths/min.
During maximal HS conditions, the ambient room sensors recorded a mean temperature of $36.4^{\circ} \mathrm{C}$ with a humidity of $24.2 \%$, which would produce a THI of 81 , which is associated with moderate-severe HS conditions and RR exceeding 85. Peak RR of 96 and RT of $41.1^{\circ} \mathrm{C}$ were reached during peak THI levels. Skin temperatures increased an average of $4.5^{\circ} \mathrm{C}$ in $\mathrm{CON}$ and $\mathrm{OG}$ cows during HS compared with TN $(P<0.0001$; Table $3)$. We did not detect a TRT $\times$ ENV interaction in the skin temperature response to HS. This increase in skin temperature was associated with an average increase in body temperature of $0.1^{\circ} \mathrm{C}$ in $\mathrm{CON}$ and $\mathrm{OG}$ cows (Table $3 ; P<0.0001$ ), and we detected a TRT $\times$ ENV interaction in this response between the 2 diets due to higher initial temperatures in CON animals in $\mathrm{TN}$ (Table $3 ; P<0.04$ ). Average RR was also increased in both CON and OG cows to 60 breaths/min (Table 3; $P$ $<0.0001$ ), which is the threshold for indicating animals are experiencing HS. We also detected a TRT $\times \mathrm{ENV}$ interaction in RR (Table $3 ; P<0.03$ ) due to lower initial RR in OG animals.

The combined effects of transportation, restraint in stalls, change in feed, cannulation, and HS reduced milk yield in all cows compared with milk yield during the on-dairy portion of the study. All physiological and milk component factors recorded were affected by the HS ENV (Table 3). The cannulation of animals and hormonal infusions used for this study likely altered feed intake and milk yield, and testing effects of OG TRT on these variables was not an objective of the study. The only TRT effect detected between the CON and OG groups was in DMI, which was lower in cows fed OG under both TN and HS conditions (Table 3; $P=0.0496)$. However, feed intake tended to remain 
unaffected in OG cows during HS but decline in CON cows (Table $3 ; P=0.07$ ). When evaluating the TRT $\times$ ENV interaction on production and responses in $\mathrm{CON}$ and OG groups, there were differences in milk yield $(P$ $=0.0041)$ and water intake $(P=0.0038)$. The TRT $\times$ ENV interaction in milk yield was due to the fact that milk yield declined in CON cows and slightly increased in OG cows during HS $(-2.0 \mathrm{~kg} / \mathrm{d}$ in CON vs. +0.3 $\mathrm{kg} / \mathrm{d}$ in OG; $P=0.004$; Table 3$)$. However, no TRT $\times$ ENV interaction was detected in FCM (Table 3; $P=$ $0.57)$. The increase in water intake was higher during $\mathrm{HS}$ in $\mathrm{OG}$ cows $(+41.16 \mathrm{~L} / \mathrm{d}$ in $\mathrm{OG}$ vs. $19.79 \mathrm{~L} / \mathrm{d}$ in CON; $P<0.004$; Table 3). Feed efficiency was reduced by HS (Table $3 ; P=0.0535$ ) in both groups, but we did not detect a TRT $\times$ ENV interaction in this response.

\section{Preinfusion Assay Data}

The preinfusion blood sample consisted of a sample collected $3 \mathrm{~d}$ before the infusion while cows were in TN. These samples were assayed for cortisol, progesterone, and ACTH concentrations. None of the analytes assayed demonstrated any effect due to TRT before infusion except serum progesterone, which was higher in $\mathrm{OG}$ cows $(13.2 \mathrm{ng} / \mathrm{mL}$ in $\mathrm{OG}$ vs. $11.1 \mathrm{ng} / \mathrm{mL}$ in CON; $P<0.0001$; Table 4). Cortisol concentrations did not differ by TRT (15.8 ng/mL in CON vs. $9.2 \mathrm{ng} /$ $\mathrm{mL}$ in $\mathrm{OG}, \pm 4.0 \mathrm{ng} / \mathrm{mL} ; P=0.28)$. These preinfusion mean values were used as covariates in analysis of the challenge samples.

\section{Effects of OG on Analyte Concentrations During Infusion Period}

The tests of significance for the 4-h period following the 2 sets of hormonal infusions (ACTH and CRH-VP) for both ENV (TN and HS) are shown in Table 5. The profiles of the time course responses are shown in Fig-

Table 4. Least squares means for preinfusion analytes

\begin{tabular}{lrrrr}
\hline & \multicolumn{2}{c}{ Treatment $^{2}(\mathrm{TRT})$} & & \\
\cline { 2 - 3 } Hormone $^{1}$ & CON & \multicolumn{1}{c}{ OG } & & TRT \\
SEM & P-value \\
\hline ACTH $(\mathrm{pg} / \mathrm{mL})$ & 184.9 & 154.9 & 43.19 & 0.5044 \\
Cortisol $(\mathrm{ng} / \mathrm{mL})$ & 15.8 & 9.2 & 4.02 & 0.2783 \\
Progesterone $(\mathrm{ng} / \mathrm{mL})$ & 11.1 & 13.2 & 0.36 & $<0.0001$ \\
bCBG $(\mathrm{ng} / \mathrm{mL})$ & 712.4 & 745.4 & 20.8 & 0.264 \\
FCI $(\mathrm{nmol} / \mathrm{mg})$ & 31.8 & 36.1 & 14.6 & 0.8385 \\
\hline
\end{tabular}

${ }^{1} \mathrm{bCBG}=$ bovine corticosteroid-binding globulin; $\mathrm{FCI}=$ free cortisol index.

${ }^{2} \mathrm{CON}=$ basal silage-based $\operatorname{diet}(\mathrm{n}=6$ cows $) . \mathrm{OG}=$ basal diet supplemented with OmniGen-AF (Phibro Animal Health Corp., Teaneck, $\mathrm{NJ} ; 56 \mathrm{~g} / \mathrm{h}$ per day; $\mathrm{n}=6$ cows). ures 2, 3, 4, and 5. There was an effect of ENV on all analytes except progesterone $(P=0.29$; Table 5$)$. There was a significant to highly significant effect of time and infusion on mean concentrations of all analytes measured, indicating that concentration of all analytes in serum was affected by infusion of the 2 releasing factors $(\mathrm{CRH}-\mathrm{VP}$ and ACTH; Table 5). A TRT $\times$ ENV interaction was detected for cortisol, bCBG, and FCI $(P=$ $0.013, P<0.009$, and $P<0.04$, respectively; Table 5). A TRT $\times$ ENV $\times$ infusion interaction was detected for all analytes, and time $\times$ TRT $\times$ ENV $\times$ infusion was highly significant for all analytes measured (Table 5), which supports the statement that all analytes were affected by infusion of the releasing factors.

\section{CRH-VP Infusion}

Serum ACTH concentrations increased following $\mathrm{CRH}-\mathrm{VP}$ infusion in all animals and peaked between 1.5 and $2 \mathrm{~h}$ postinfusion (Figure 2A, B; Table 5; $P$ $<0.0001$ ). Serum ACTH concentrations did not differ between $\mathrm{CON}$ and $\mathrm{OG}$ cows following infusion of $\mathrm{CRH}-$ VP $(P=0.19$; Table 5$)$. There was an effect of ENV on ACTH response, with greater values detected following CRH-VP challenge during HS $(P<0.001$; Table $5)$. However, there was no TRT $\times \mathrm{ENV}$ interaction in ACTH response to CRH-VP infusion $(P=0.645$; Table $5)$.

Following CRH-VP infusion serum cortisol concentrations increased in both TN and HS, but this increase was greater in HS (Figure 2C, D; Table 5; $P<0.0001$ ). Serum cortisol values declined slowly following peak concentrations at $30 \mathrm{~min}$ in TN and $1.5 \mathrm{~h}$ in HS. Cortisol values did not reach baseline until $6 \mathrm{~h}$ following infusion of CRH-VP in both TN and HS environments. Additionally, the cortisol response to $\mathrm{CRH}-\mathrm{VP}$ infusion was markedly lower in OG-fed animals compared with CON in HS (Figure 2C, D; Table 5; $P=0.013$ ).

Both OG and CON cows displayed increased serum progesterone concentrations following CRH-VP infusion (Table 5; Figure 2E, F; $P<0.0001$ ). Contrary to findings for $\mathrm{ACTH}$ and cortisol, we did not detect an effect of HS on serum progesterone concentrations in this model. Additionally, we failed to detect an effect of TRT or a TRT $\times$ ENV interaction (Table 5; $P=$ 0.56 and $P=0.89$, respectively) on serum progesterone concentrations following CRH-VP infusion.

Serum bCBG concentrations were increased by $\mathrm{CRH}-$ VP infusion (Figure 3A, B; Table 5; $P<0.0001$ ). The increase in serum bCBG was delayed and did not occur until 3 to $4 \mathrm{~h}$ following infusion of CRH-VP (Figure $3 \mathrm{~A}, \mathrm{~B})$. The bCBG response was also greater during HS compared with TN $(P<0.0001)$ in cows infused with 


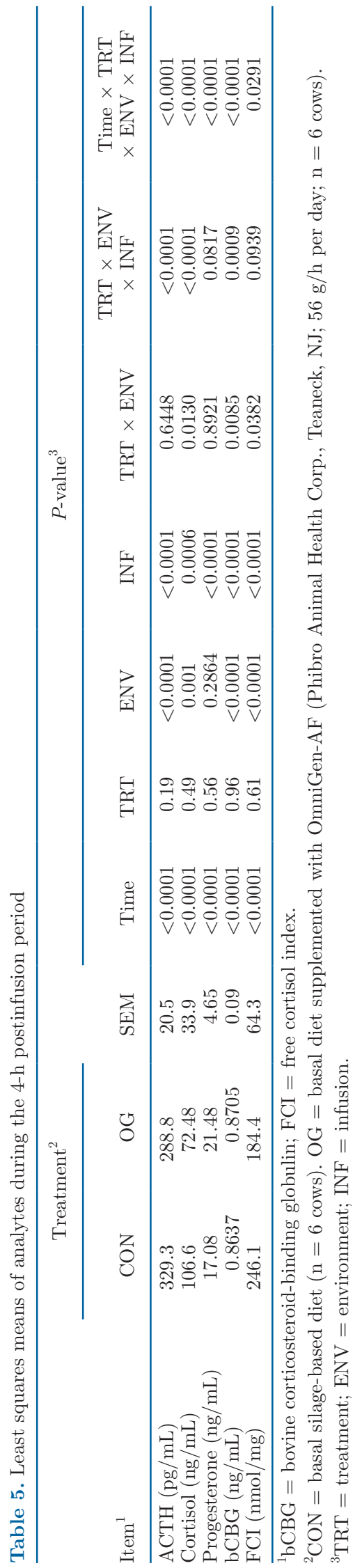

CRH-VP. We also detected a TRT $\times$ ENV interaction in the bCBG response, with a greater increase in bCBG during HS in CON compared with OG animals (Figure $3 \mathrm{~A}, \mathrm{~B}$; Table $5 ; P<0.009$ ).

The FCI increased rapidly and reached peak concentrations 1 to $2 \mathrm{~h}$ after infusion of $\mathrm{CRH}-\mathrm{VP}$ (Figure 3C, D). There was also a strong effect of ENV on the FCI, with greater concentrations during HS compared with TN $(P<0.0001 ;$ Table 5$)$. We failed to detect an effect of TRT on FCI (Table $5 ; P=0.61$ ). However, there was a TRT $\times$ ENV interaction, with FCI being lower in OG animals during HS (Figure 3C, D; Table 5; $P<0.04$ ).

\section{ACTH Infusion}

As expected, ACTH concentrations increased in both TRT groups following ACTH infusion (Figure 4A, B). We failed to detect an effect of TRT or a TRT $\times$ ENV interaction in ACTH response $(P=0.19$ and $P$ $=0.0 .645 ;$ Table 5). The ACTH response to ACTH infusion was more rapid than the ACTH response to $\mathrm{CRH}-\mathrm{VP}$, with peak responses detected at $1 \mathrm{~h}$ compared with 1.5 to $2 \mathrm{~h}$ (Figure 2A, B; Figure 4A, B). We also detected a TRT $\times \mathrm{ENV} \times$ infusion interaction in the cortisol response to the 2 releasing factors (Table 5; $P<0.0001)$. The increase in ACTH to CRH-VP was more extended than the increase in ACTH following ACTH infusion, and the response was lower following both infusions in OG animals (Figure 2A, B; Figure $4 \mathrm{~A}, \mathrm{~B})$.

Serum cortisol was increased by ACTH in both TRT groups, but the response was reduced in OG cows during acute HS (Figure 4C, D; Table 5; TRT $\times \mathrm{ENV}, P$ $=0.013)$. We failed to detect an effect of TRT on mean cortisol response to ACTH in the 2 dietary groups (Table 5; $P=0.49$ ). However, there was a TRT $\times \mathrm{ENV}$ $x$ infusion interaction in the cortisol response to the 2 releasing factors (Table 5; $P<0.0001$ ). The cortisol response to CRH-VP was more prolonged than the response to ACTH; this response was greater in HS compared with $\mathrm{TN}$ in both groups but always was lower in OG compared with CON animals (Table 5; Figure 2C, D; Figure 4C, D). Serum progesterone concentrations also increased following ACTH infusion in both TRT groups, but we did not detect an effect of TRT or a TRT $\times$ ENV interaction in this response (Figure 4E, F; Table 5).

Serum bCBG concentrations were increased following $\mathrm{ACTH}$ infusion, but the increase did not begin until approximately $1.5 \mathrm{~h}$ following infusion (Figure $5 \mathrm{~A}, \mathrm{~B}$ ). We did not detect an effect of TRT on bCBG concentration but did detect a TRT $\times$ ENV interaction in serum bCBG response to ACTH (Figure 5A, B; Table 5; $P=$ 

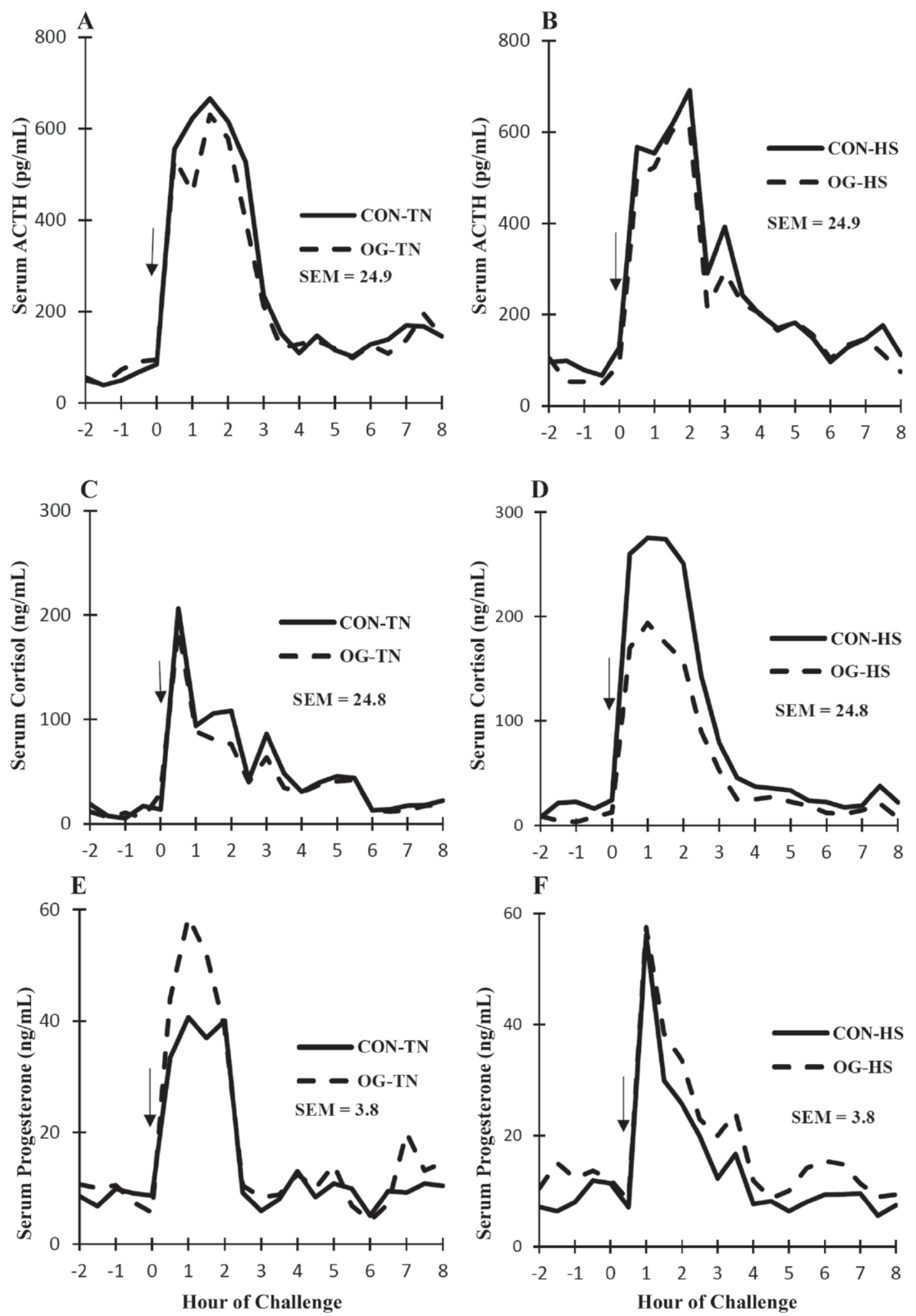

Figure 2. Serum cortisol, ACTH, and progesterone response profiles within thermoneutral (TN; temperature-humidity index <68) or heat stress (HS; temperature-humidity index $>68$ for $12 \mathrm{~h} / \mathrm{d}$ ) environments following corticotropin-releasing hormone and vasopressin infusion in cows fed a basal silage-based diet (CON; $\mathrm{n}=6$ cows) and in cows fed the basal diet supplemented with OmniGen-AF (OG; Phibro Animal Health Corp., Teaneck, NJ; $56 \mathrm{~g} / \mathrm{h}$ per day; $\mathrm{n}=6 \mathrm{cows})$. Arrow at time $0 \mathrm{~h}$ represents time of infusion. Effect of infusion was highly significant for all 3 variables. Effect of environment was highly significant for ACTH and cortisol but not progesterone. A treatment $\times$ environment interaction was detected for cortisol $(P<0.01)$ but not ACTH or progesterone. A treatment $\times$ environment $\times$ infusion interaction was highly significant $(P<0.001)$ for ACTH and cortisol but not progesterone. See Table 5 for significance values. 
0.0085), with slightly higher bCBG concentrations in OG animals during HS.

The FCI response to ACTH was different compared with the bCBG response in that FCI increased immediately following infusion of ACTH and reached peak levels at approximately the same time the bCBG concentration began increasing (Figure 5C, D). We did not detect an effect of TRT on mean CBG concentrations postinfusion. However, we did detect a TRT $\times \mathrm{ENV}$ interaction, with lower FCI in cows fed OG during HS but not TN (Figure 5C, D; Table 5; $P<0.04$ ).

\section{Postinfusion Assay Data}

Postinjection infusion blood analytes were compared by TRT and TRT $\times$ ENV. Dietary TRT did not affect any of the analytes (cortisol, progesterone, bCBG) measured during the postinfusion period $(8$ and $12 \mathrm{~d}$
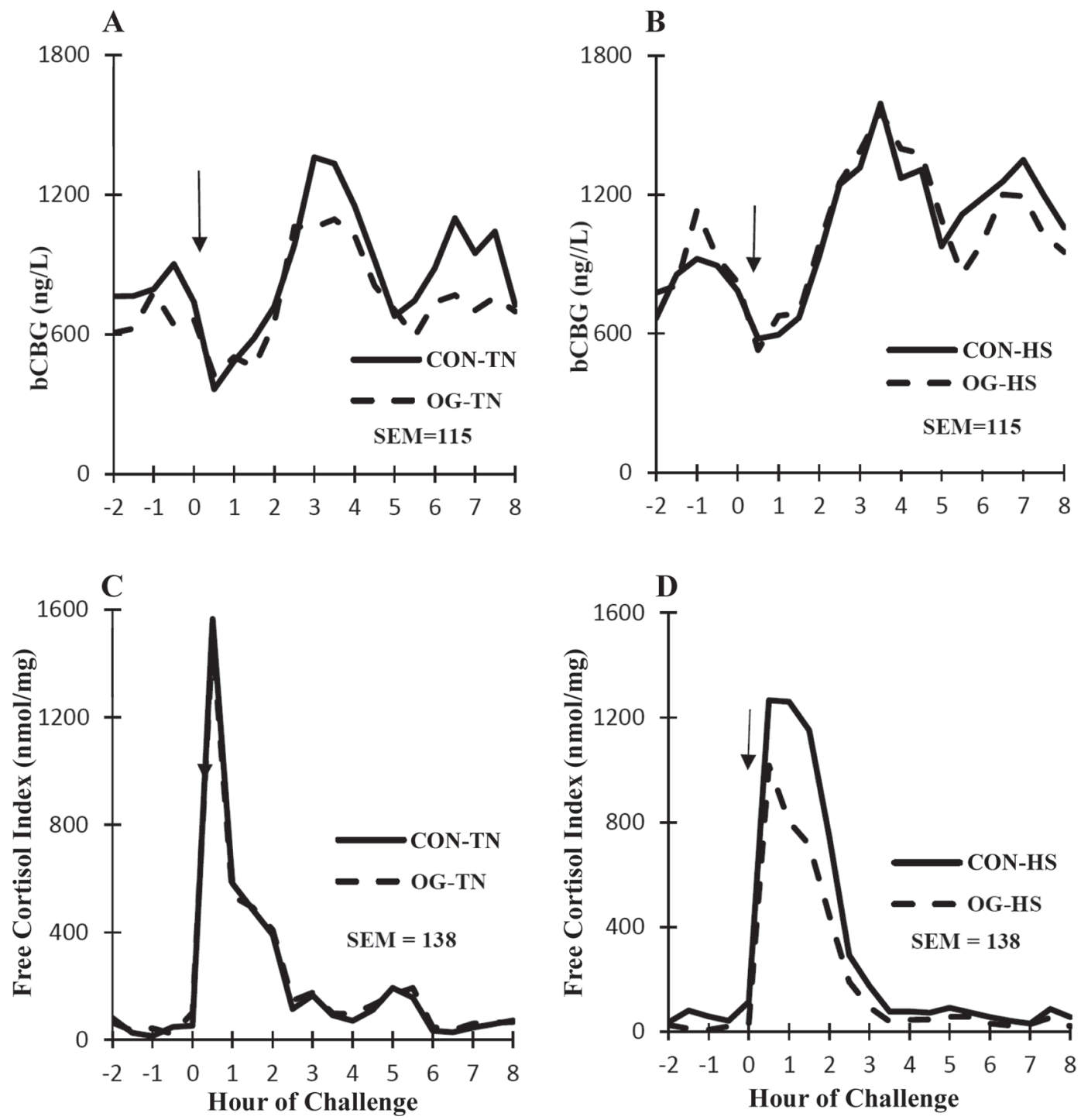

Figure 3. Serum bovine corticosteroid-binding globulin (bCBG) and free cortisol index response profiles within thermoneutral (TN; temperature-humidity index $<68$ ) or heat stress (HS; temperature-humidity index $>68$ for $12 \mathrm{~h} / \mathrm{d}$ ) environments following corticotropin-releasing hormone and vasopressin infusion in cows fed a basal silage-based diet (CON; $\mathrm{n}=6$ cows) and in cows fed the basal diet supplemented with OmniGen-AF (OG; Phibro Animal Health Corp., Teaneck, NJ; $56 \mathrm{~g} / \mathrm{h}$ per day; $\mathrm{n}=6$ cows). Arrow at time 0 h represents time of infusion. Effect of infusion was highly significant for both variables $(P<0.0001)$. Environment effects were also highly significant for both variables $(P$ $<0.0001)$. Treatment $\times$ environment interactions were also detected for both variables $(P<0.009$ and $P<0.04)$. Treatment $\times$ environment $\times$ infusion interaction was detected for bCBG but not free cortisol index $(P<0.0009$ and $P<0.09)$. 
A

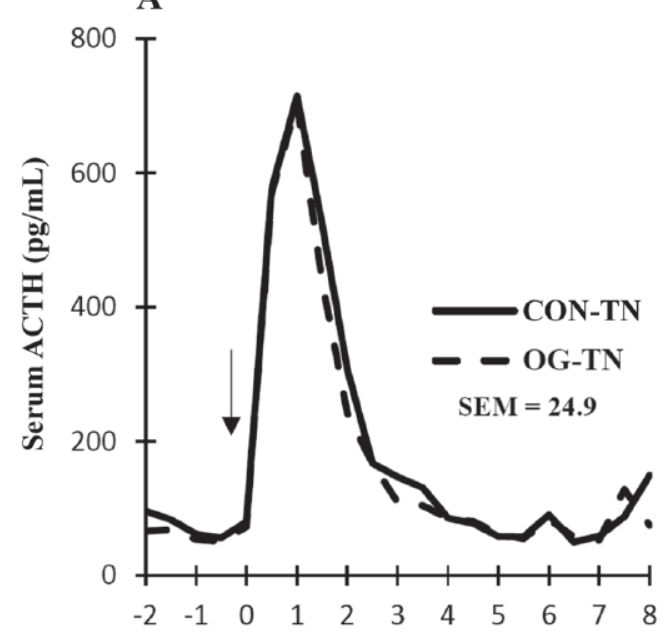

C

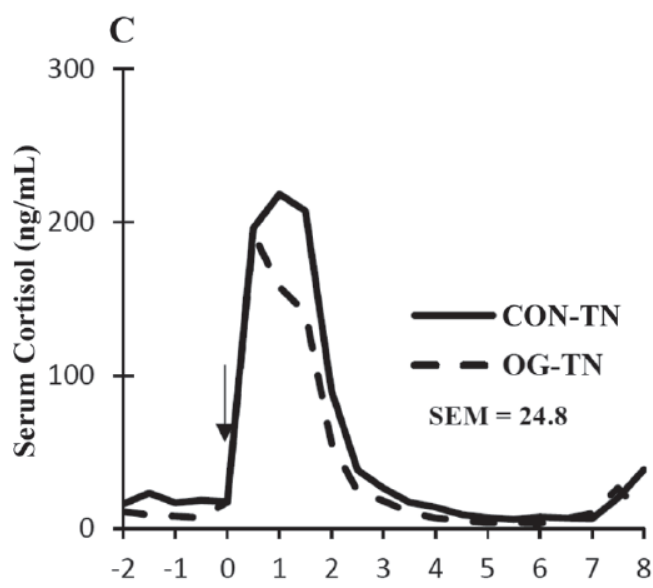

$\mathbf{E}$

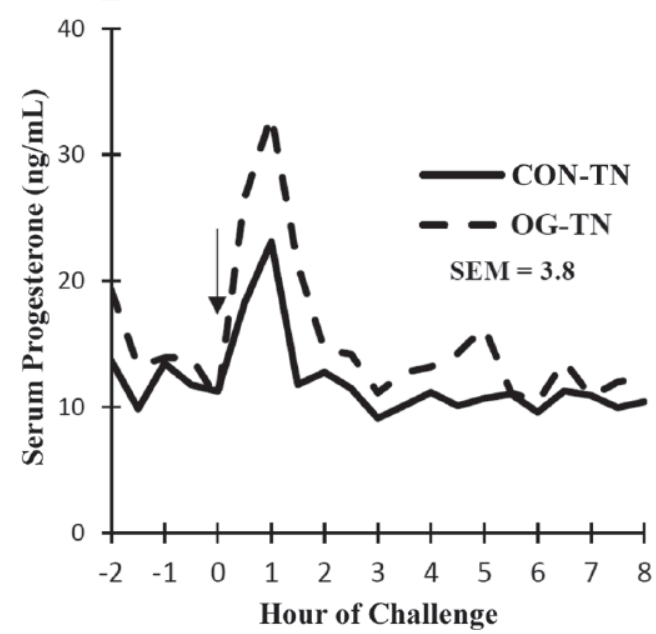

B
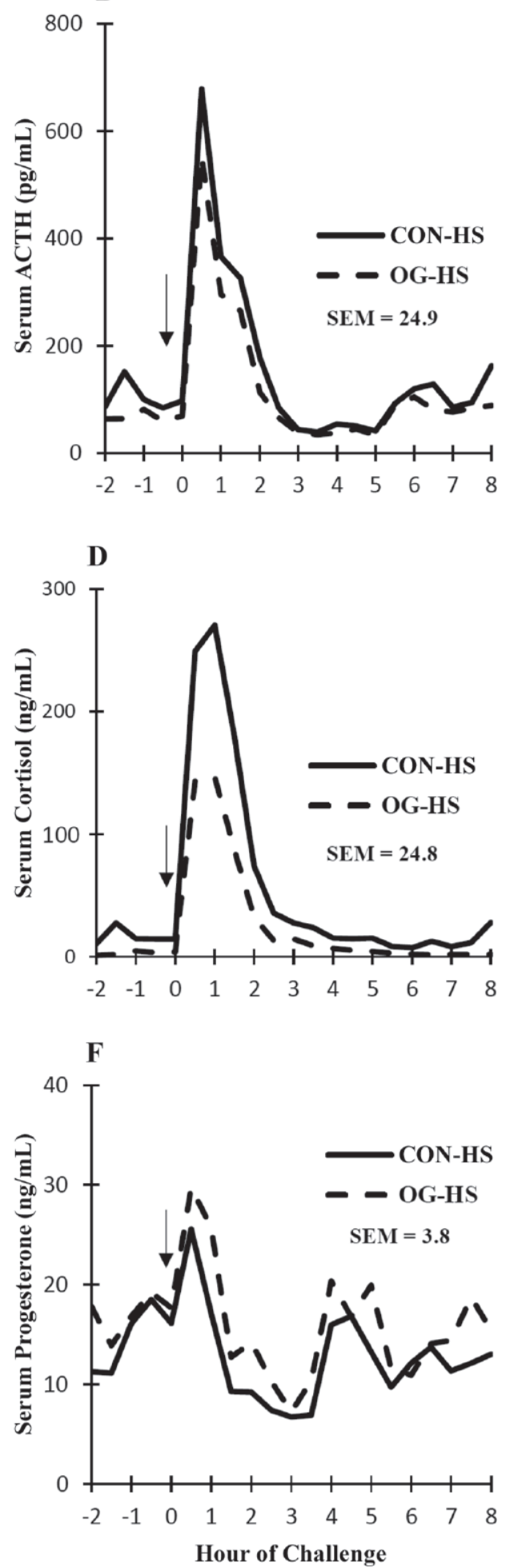

Figure 4. Serum cortisol, ACTH, and progesterone response profiles within thermoneutral (TN; temperature-humidity index $<68$ ) or heat stress (HS; temperature-humidity index $>68$ for $12 \mathrm{~h} / \mathrm{d}$ ) environments following ACTH infusion in cows fed a basal silage-based diet (CON; $\mathrm{n}$ $=6$ cows) and in cows fed the basal diet supplemented with OmniGen-AF (OG; Phibro Animal Health Corp., Teaneck, NJ; 56 g/h per day; $\mathrm{n}$ $=6$ cows). Arrow at time $0 \mathrm{~h}$ represents time of infusion. Effect of infusion was highly significant for all 3 variables. Environment was highly significant for ACTH and cortisol but not progesterone. A treatment $\times$ environment interaction was detected for cortisol $(P<0.01)$ but not ACTH or progesterone. A treatment $\times$ environment $\times$ infusion interaction was highly significant $(P<0.001)$ for ACTH and cortisol but not progesterone. See Table 5 for significance values. 
A
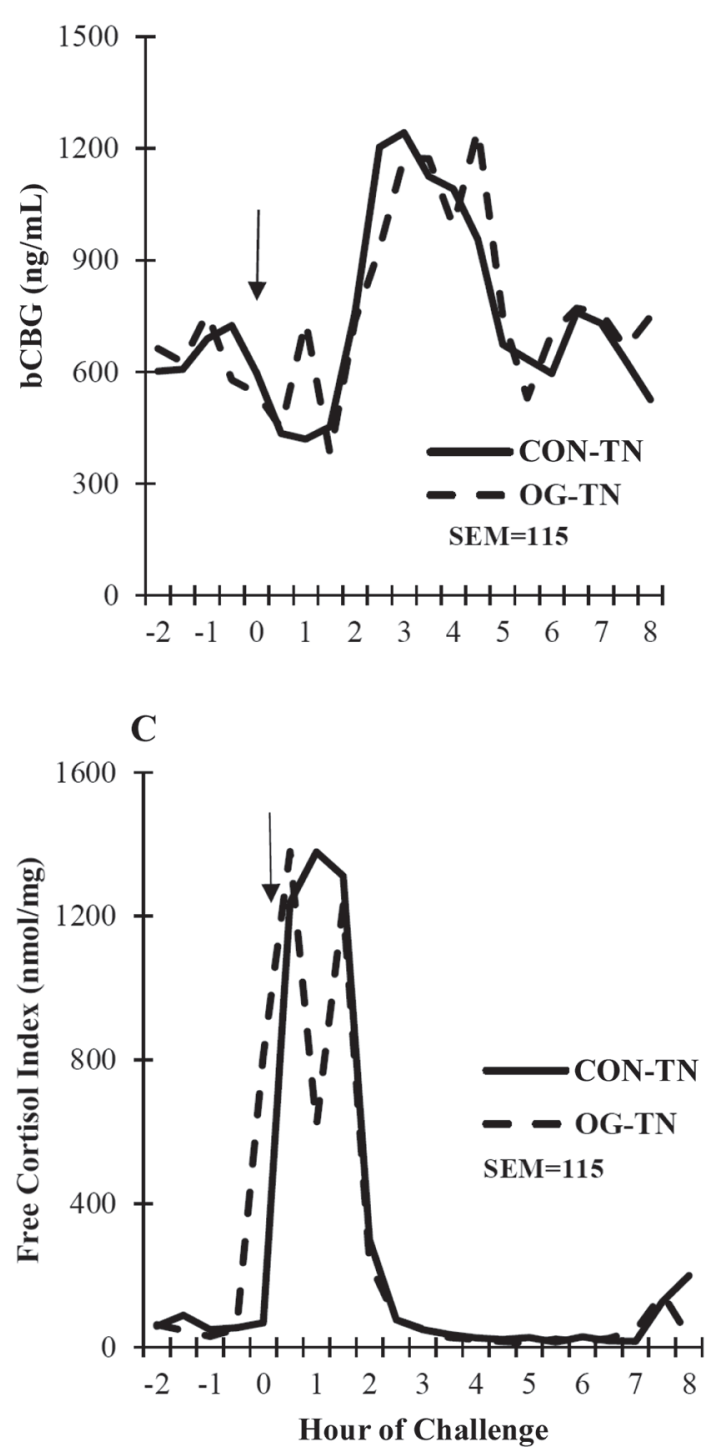

B
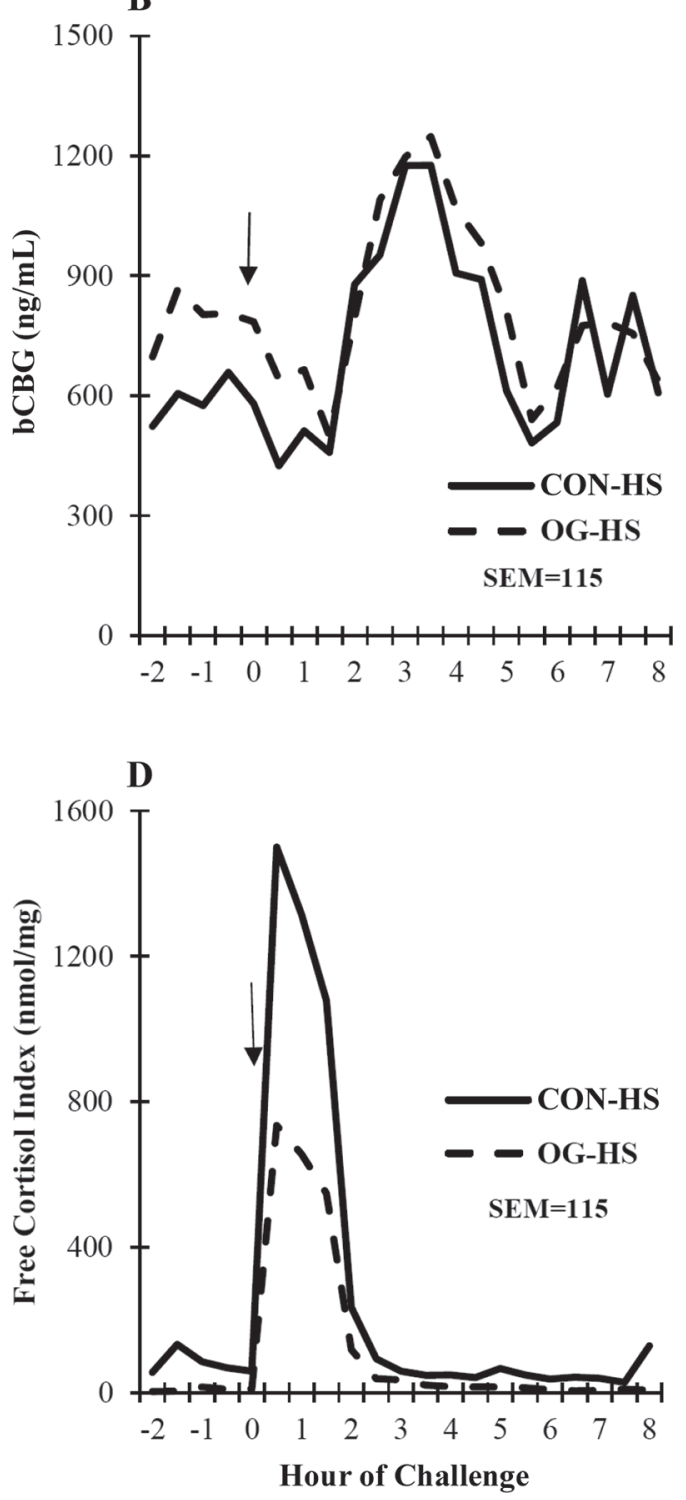

Figure 5. Serum bovine corticosteroid-binding globulin (bCBG) and free cortisol index time trends within thermoneutral (TN; temperaturehumidity index $<68$ ) or heat stress (HS; temperature-humidity index $>68$ for $12 \mathrm{~h} / \mathrm{d}$ ) environments following ACTH infusion in cows fed a basal silage-based diet (CON; $\mathrm{n}=6$ cows) and in cows fed the basal diet supplemented with OmniGen-AF (OG; Phibro Animal Health Corp., Teaneck, NJ; $56 \mathrm{~g} / \mathrm{h}$ per day; $\mathrm{n}=6$ cows $)$. Arrow at time $0 \mathrm{~h}$ represents time of infusion. Effect of infusion and environment was highly significant for both variables $(P<0.0001)$. Treatment $\times$ environment interactions were also detected for both variables $(P<0.009$ and $P<0.04)$. Treatment $\times$ environment $\times$ infusion interaction was detected for bCBG but not free cortisol index $(P<0.0009$ and $P<0.09)$.

following the infusions), and there was no TRT $\times$ day effect (data not shown).

\section{DISCUSSION}

The THI values and physiological responses in cows during HS indicate that the cows were experiencing moderate to severe HS. Animals experiencing the HS environment displayed increased skin and core temperatures and RR. They also displayed reduced feed intake and milk yield and increased water intake in response to the HS environment. Acute exposure to HS was also associated with increased adrenal response to the releasing factors in both $\mathrm{CON}$ and $\mathrm{OG}$ animals. Thus, the release of cortisol to both ACTH and CRHVP was increased in acute HS compared with TN in both CON and OG animals.

The effect of acute HS on increasing blood cortisol concentrations is well documented (Gwazdauskas et al., 1972; Johnson and Vanjonack, 1976; Collier et 
al., 1982). However, chronic HS is not associated with increased plasma cortisol (Collier et al., 1982). This seems to be associated with the requirement for cortisol to initiate intracellular release of heat shock proteins from glucocorticoid receptors and to initiate synthesis of heat shock proteins (Collier et al., 2008). Thus, the acute increase in cortisol to HS is a component of the acute heat shock response in cattle and is very likely involved in regulating in part the acute HS response.

The ACTH response to releasing factors was not affected by ENV but was slightly reduced in OG animals compared with CON animals during HS. This may have contributed to the lower cortisol response to both releasing factors in OG animals during acute HS.

The most striking response detected in the study was the blunted cortisol and FCI response to both CRHVP and ACTH in OG cows during HS. This suggests that the adrenal response to ACTH was reduced during acute stress response and agrees with Hall et al. (2018), who reported that cortisol levels in OG cows were reduced during acute HS.

The increased concentration of serum cortisol to releasing factors in the HS ENV was also associated with increased serum progesterone, presumably from the adrenal gland in response to the releasing factor infusions. Previously, Abilay et al. (1975), Roman-Ponce et al. (1981), and Trout et al. (1998) reported increases in serum progesterone of lactating dairy cows exposed to HS, whereas others reported no change (Biggers et al., 1987; Wise et al., 1988).

Although the increase in progesterone following releasing factor infusion appeared to be enhanced in OG cows, we failed to detect a TRT or TRT $\times$ ENV interaction in progesterone response to releasing factors. This may be because these cows were not pregnant and were in differing stages of their estrous cycle. Therefore, progesterone of ovarian origin may have contributed to variation preventing detection of TRT effects. Additional studies in synchronized animals or steers are warranted to examine this further.

Bovine CBG concentrations were increased by CRH$\mathrm{VP}$ and ACTH infusion in both CON and OG cows during TN conditions. This response increased in HS conditions, especially by CRH-VP in both CON and OG cows. The liver synthesizes and stores CBG that it releases in response to stress stimuli (Qian et al., 2011). The role of bCBG is to dampen the effects of increased cortisol secretion and delay the availability of the increased cortisol to tissues by keeping it in circulation (Coolens et al., 1987; Le Roux et al., 2002). These results suggest that ACTH and CRH-VP may have a role in regulating secretion of bCBG into circulation. We failed to detect an effect of feeding OG on circulating bCBG.
The FCI is considered a reliable indicator of free cortisol in circulation (Le Roux et al., 2002). This is an important measure because $80 \%$ of cortisol in circulation is bound to CBG and is unavailable to tissues (Coolens et al., 1987). In this study, the FCI was rapidly increased following both CRH-VP and ACTH. However, the FCI response was reduced in OG cows, especially during acute HS. This suggests that the amount of free cortisol available to tissues in OG cows during acute HS was reduced compared with CON cows. Additionally, the blunted FCI response in OG cows appears to be due primarily to reduced cortisol secretion rather than increased bCBG secretion from the liver.

It is well established that HS adversely affects immunity in dairy cows (Baumgard and Rhoads, 2012; Baumgard et al., 2015; Dahl et al., 2016). The immunomodulatory feed supplement OG has been shown to improve immune function and reduce physiological stress responses of dairy cows exposed to HS (Brandão et al., 2016; Leiva et al., 2017; Skibiel et al., 2017). It is also well established that considerable cross-talk occurs between the endocrine and immune systems (Bradford et al., 2016), and glucocorticoids are known to suppress immune function in dairy cows (Mallard et al., 1998; Sordillo, 2016). Cortisol concentrations are increased by acute HS, and this effect is suppressed in cows fed OG (Johnson and Vanjonack, 1976; Wise et al., 1988; Hall et al., 2018). However, chronic HS is not associated with altered cortisol concentrations in $\mathrm{CON}$ or $\mathrm{OG}$ cows (Brandão et al., 2016; Leiva et al., 2017; Hall et al., 2018).

\section{CONCLUSIONS}

We tested the hypothesis that feeding OG to lactating dairy cows would alter the adrenal response to pituitary $(\mathrm{ACTH})$ and hypothalamic (CRH-VP) factors known to cause release of cortisol under acute HS conditions. The data from this study support this hypothesis and are the first to demonstrate that this difference is apparent under acute HS conditions. Specifically, the increase in plasma cortisol with both $\mathrm{ACTH}$ and CRH-VP challenge was reduced during acute HS conditions in lactating dairy cows fed OG. The blunted response in cortisol secretion was also associated with a slightly reduced ACTH response to $\mathrm{CRH}-\mathrm{VP}$ in OG animals. Progesterone concentrations in lactating dairy cows exposed to HS are increased (Gwazdauskas et al., 1972; Roman-Ponce et al., 1981), and this increase may be affected by length of the stress period (De Rensis and Scaramuzzi, 2003). According to a study by Wise et al. (1988), lactating dairy cows exposed to acute HS exhibited similar concentrations of serum progesterone but displayed increased concentration of serum cortisol 
compared with a CON group kept in an air-conditioned tiestall barn. Overall, the results presented here suggest that further investigation of adrenal metabolism in cows fed OG is warranted to precisely determine which cellular mechanisms are altered by OG.

\section{ACKNOWLEDGMENTS}

The authors acknowledge support from Phibro Animal Health Corporation (Teaneck, NJ) in conducting this study. R. Collier serves as a consultant for Phibro Animal Health as well. The authors have stated no other conflicts of interest.

\section{REFERENCES}

Abilay, T. A., H. D. Johnson, and M. Madan. 1975. Influence of environmental heat on peripheral serum progesterone and cortisol during the bovine estrous cycle. J. Dairy Sci. 58:1836-1840. https: //doi.org/10.3168/jds.S0022-0302(75)84795-3.

Anton, A., and G. Solcan. 2012. Adrenocortical response in cows after injection of adrenocorticotropic hormone. In Scientific Works. C Series. Veterinary Medicine, Vol. 17. University of Agronomical Sciences and Veterinary Medicine, Bucharest, Romania.

Baumgard, L. H., and R. Rhoads. 2012. Ruminant Nutrition Symposium: Ruminant production and metabolic responses to heat stress. J. Anim. Sci. 90:1855-1865. https://doi.org/10.2527/jas .2011-4675.

Baumgard, L. H., A. Keating, J. W. Ross, and R. P. Rhoads. 2015. Effects of heat stress on the immune system, metabolism and nutrient partitioning: Implications on reproductive success. Rev. Bras. Reprod. Anim. 39:173-183.

Biggers, B. G., R. D. Geisert, R. P. Wetteman, and D. S. Buchanan. 1987. Effect of heat stress embryonic development in the beef cow. J. Anim. Sci. 64:1512-1518. https://doi.org/10.2527/jas1987 $.6451512 x$.

Bradford, B. J., K. Yuan, and C. Ylioja. 2016. Managing complexity: Dealing with systemic crosstalk in bovine physiology. J. Dairy Sci. 99:4983-4996. https://doi.org/10.3168/jds.2015-10271.

Brandão, A. P., R. F. Cooke, F. N. Corrá, M. B. Piccolo, R. Gennari, T. Leiva, and J. L. M. Vasconcelos. 2016. Physiologic, health, and production responses of dairy cows supplemented with an immunomodulatory feed ingredient during the transition period. J. Dairy Sci. 99:5562-5572. https://doi.org/10.3168/jds.2015-10621.

Buntyn, J. O., S. E. Sieren, C. J. Bittner, D. Burken, G. E. Erickson, N. C. Burdick Sanchez, J. A. Carroll, S. J. Jones, T. B. Schmidt, K. C. Dehann, and T. J. Wistuba. 2016. Effects of feeding OmniGen-AF on immune function, performance, and carcass characteristics during the feeding period. Nebraska Beef Cattle Report No. 864. University of Nebraska, Lincoln. https://digitalcommons.unl .edu/animalscinbcr/864/.

Carroll, J. A., R. R. Reuter, C. C. Chase Jr., S. W. Coleman, D. G. Riley, D. E. Spiers, J. D. Arthington, and M. L. Galyean. 2009. Profile of the bovine acute-portion response following an intravenous bolus-dose lipopolysaccharide challenge. Innate Immun. 15:81-89. https://doi.org/10.1177/1753425908099170.

Carroll, T., D. Aron, J. Findling, and B. Tyrrell. 2011. Glucocorticoids and adrenal androgens. Pages 395-440 in Greenspan's Basic and Clinical Endocrinology. D. G. Gardner and D. Shoback, ed. McGraw-Hill, New York, NY.

Collier, R. J., D. K. Beede, W. W. Thatcher, L. A. Israel, and C. J. Wilcox. 1982. Influences of environment and its modification on dairy animal health and production. J. Dairy Sci. 65:2213-2227. https://doi.org/10.3168/jds.S0022-0302(82)82484-3.
Collier, R. J., J. L. Collier, R. P. Rhoads, and L. H. Baumgard. 2008. Genes involved in the bovine heat stress response. J. Dairy Sci. 91:445-454. https://doi.org/10.3168/jds.2007-0540.

Collier, R. J., and K. G. Gebremedhin. 2015. Thermal biology of domestic cows. Annu. Rev. Anim. Biosci. 3:10.1-10.20.

Coolens, J. L., H. vanBaelen, and W. Heyns. 1987. Clinical use of unbound plasma cortisol as calculated from total cortisol and corticosteroid-binding globulin. J. Steroid Biochem. 26:197-202. https: //doi.org/10.1016/0022-4731(87)90071-9.

Dahl, G. E., S. Tao, and A. P. A. Monteiro. 2016. Effects of lategestation heat stress immunity and performance of calves. J. Dairy Sci. 99:3193-3198. https://doi.org/10.3168/jds.2015-9990.

De Rensis, F., and R. J. Scaramuzzi. 2003. Heat stress and seasonal effects on reproduction in the dairy cow - A review. Theriogenology 60:1139-1151. https://doi.org/10.1016/S0093-691X(03)00126-2.

Fabris, T. F., J. Laporta, F. N. Corra, Y. M. Torres, D. J. Kirk, D. J. McLean, J. D. Chapman, and G. E. Dahl. 2017. Effect of nutritional immunomodulation and heat stress during the dry period on subsequent performance of cows. J. Dairy Sci. 100:6733-6742. https://doi.org/10.3168/jds.2016-12313.

Gwazdauskas, F. C., W. W. Thatcher, and C. J. Wilcox. 1972. Adrenocorticotropin alteration of bovine peripheral serum concentrations of cortisol, corticosterone, and progesterone. J. Dairy Sci. 55:1165-1169. https://doi.org/10.3168/jds.S0022-0302(72)85640 $-6$.

Hall, L. W., F. Villar, J. D. Chapman, D. J. McLean, N. M. Long, Y. Xiao, J. L. Collier, and R. J. Collier. 2018. An evaluation of an immunomodulatory feed ingredient in heat-stressed lactating Holstein cows: Effects on hormonal, physiological and production responses. J. Dairy Sci. 101:7095-7105. https://doi.org/10.3168/ jds.2017-14210.

Johnson, H. D., and W. Vanjonack. 1976. Effects of ENVal and other stressors on blood hormone patterns in lactating cows. J. Dairy Sci. 59:1603-1617. https://doi.org/10.3168/jds.S0022-0302(76)84413 $-\mathrm{X}$.

Lay, D. C. Jr., T. H. Friend, R. D. Randel, O. C. Jenkins, D. A. Neuendorff, G. M. Kapp, and D. M. Bushong. 1996. Adrenocorticotropic hormone dose response and some physiological effects of transportation on pregnant Brahman cattle. J. Anim. Sci. 74:1806-1811. https://doi.org/10.2527/1996.7481806x.

le Roux, C. W., G. A. Chapman, W. M. Kong, W. S. Dhillo, J. Jones, and J. Alaghband-Zadeh. 2003. Free cortisol index is better than serum total cortisol in determining hypothalamic-pituitary-adrenal status in patients undergoing surgery. J. Clin. Endocrinol. Metab. 88:2045-2048. https://doi.org/10.1210/jc.2002-021532.

Le Roux, C. W., S. Sivakumaran, J. Alaghband-Zadeh, W. Dhillo, W. M. Kong, and M. J. Wheeler. 2002. Free cortisol index as a surrogate marker for serum free cortisol. Ann. Clin. Biochem. 39:406-408. https://doi.org/10.1258/000456302760042182.

Leiva, T., R. F. Cooke, A. P. Brandão, K. M. Schubach, L. F. D. Batista, M. F. Miranda, E. A. Colombo, R. O. Rodrigues, J. R. G. Junior, R. L. A. Cerri, and J. L. M. Vasconcelos. 2017. Supplementing an immunomodulatory feed ingredient to modulate thermoregulation, physiologic, and production responses in lactating dairy cows under heat stress conditions. J. Dairy Sci. 100:48294838. https://doi.org/10.3168/jds.2016-12258.

Mallard, B. A., J. Dekkers, M. J. Ireland, K. E. Lesslie, S. Sharif, C. Lacey Vankampen, L. Wager, and B. N. Wilkie. 1998. Alteration in immune responsiveness during the peripartum period and its ramification on dairy cow and calf health. J. Dairy Sci. 81:585-595.

Ortiz-Marty, R. J., A. Lewandowski, J. D. Chapman, and I. KanevskyMullarky. 2017. A commercial immune modulating feed additive restores L-selectin and CCL5 expression following dexamethasone treatment of murine immune cells in a MyD88-dependent manner. J. Dairy Sci. 100:6422-6428. https://doi.org/10.3168/jds.2016 $-11783$.

Qian, X., S. K. Droste, M. Gutièrrez-Mecinas, A. Collins, F. Kersanté, J. M. H. M. Reul, and A. C. E. Linthorst. 2011. A rapid release of corticosteroid-binding globulin from the liver restrains the glucocorticoid hormone response to acute stress. Endocrinology 152:3738-3748. https://doi.org/10.1210/en.2011-1008. 
Roberts, M. P., H. G. Kattesh, G. A. Baumbach, B. E. Gillespie, J. D. Godkin, J. F. Schneider, and A. M. Saxton. 2003. Age-related changes in porcine corticosteroid-binding globulin (pBCBG) as determined by an enzyme-linked immunosorbent assay. Domest. Anim. Endocrinol. 24:323-339. https://doi.org/10.1016/S0739 -7240(03)00011-0.

Roman-Ponce, H., W. W. Thatcher, and C. J. Wilcox. 1981. Hormonal interrelationships and physiological responses of lactating dairy cows to a shade management system in a subtropical environment. Theriogenology 16:139-154. https://doi.org/10.1016/0093 -691X(81)90097-2.

Ryman, V. E., S. C. Nickerson, F. M. Kautz, D. J. Hurley, L. O. Ely, Y. Q. Wang, and N. E. Forsberg. 2013. Effect of dietary supplementation on the antimicrobial activity of blood leukocytes isolated from Holstein heifers. Res. Vet. Sci. 95:969-974. https://doi .org/10.1016/j.rvsc.2013.09.009.

Siiteri, P. K., J. T. Murai, G. L. Hammond, J. A. Nisker, W. J. Raymore, and R. W. Kuhn. 1982. The serum transport of steroid hormones. Recent Prog. Horm. Res. 38:457-510.

Skibiel, A. L., T. F. Fabris, F. N. Corrá, Y. M. Torres, D. J. McLean, J. D. Chapman, D. F. Kirk, G. E. Dahl, and J. Laporta. 2017. Effects of feeding an immunomodulatory supplement to heat-stressed or actively cooled cows during late gestation on postnatal immunity, health, and growth of calves. J. Dairy Sci. 100:7659-7668. https://doi.org/10.3168/jds.2017-12619.

Sordillo, L. M. 2016. Nutritional strategies to optimize dairy cattle immunity. J. Dairy Sci. 99:4967-4982. https://doi.org/10.3168/jds .2015-10354.

Trout, J. P., L. R. McDowell, and P. J. Hansen. 1998. Characteristics of the estrous cycle and antioxidant status of lactating Holstein cows exposed to heat stress. J. Dairy Sci. 81:1244-1250. https:// doi.org/10.3168/jds.S0022-0302(98)75685-1.
Wang, Y., S. B. Puntenney, and N. Forsberg. 2004. Identification of the mechanisms by which Omnigen-AF, a nutritional supplement, augments immune function in ruminant livestock. Pages 349-352 in Proc. ASAS West Sect, Phoenix, AZ.

Wang, Y. Q., S. B. Puntenney, J. L. Burton, and N. E. Forsberg. 2007. Ability of a commercial feed additive to modulate expression of innate immunity in sheep immunosuppressed with dexamethasone. Animal 1:945-951.

Wise, M. E., D. Armstrong, J. Huber, R. Hunter, and F. Wiersma. 1988. Hormonal alterations in the lactating dairy cow in response to thermal stress. J. Dairy Sci. 71:2480-2485. https://doi.org/10 .3168/jds.S0022-0302(88)79834-3.

Zimbelman, R., R. Rhoads, M. Rhoads, G. Duff, L. Baumgard, and R. Collier. 2009. A re-evaluation of the impact of temperature humidity index (THI) and black globe humidity index (BGHI) on milk production in high producing dairy cows. Pages $26-27$ in Proc. Southwest Nutrition and Management Conference, Tempe, Arizona.

\section{ORCIDS}

M. L. McBride @ https://orcid.org/0000-0002-5770-6886

N. C. Burdick Sanchez ㄴ https://orcid.org/0000-0003-0709-871X

J. A. Carroll @ https://orcid.org/0000-0002-0202-4888

J. L. Collier @ https://orcid.org/0000-0001-8709-8845

D. J. McLean (1) https://orcid.org/0000-0001-6151-2796

R. J. Collier @ https://orcid.org/0000-0002-1552-9711 